\title{
Predicting the Destiny after Severe Traumatic Brain Injury; Multi Organ Dysfunction Syndrome (MODS) or Sequential Organ Failure Assessment (SOFA)?
}

\author{
Sara Ramtinfar*, Yousefzadeh Chabok Sh, Jafari Chari A and Kazemnejad Leili E \\ Guilan University of Medical Science, Trauma Research Center, Guilan, Iran \\ *Corresponding author: Sara Ramtinfar, Guilan University of Medical Science, Trauma Research Center, Guilan, Iran, Tel: +989358352669; Fax: +982166427181; E- \\ mail: dr.ramtinfar@yahoo.com
}

Received date: November 10, 2016; Accepted date: December 28, 2016; Published date: December 30, 2016

Copyright: (c) 2016 Ramtinfar S, et al. This is an open-access article distributed under the terms of the Creative Commons Attribution License, which permits unrestricted use, distribution, and reproduction in any medium, provided the original author and source are credited.

\begin{abstract}
Purpose: To compare the outcome prediction ability of SOFA and MOD scoring systems, in the subset of ICU patients with severe traumatic brain injury.

Materials and Methods: We performed a descriptive analytic study at Poursina hospital, a tertiary care trauma center. A number of 83 patients with severe traumatic brain injury who admitted to ICU between November 2012 and December 2013 were included. SOFA and MOD scores were calculated for each patient on a daily basis and areas under receiver operating characteristic curves were used to compare the discriminative ability of two scoring systems.
\end{abstract}

Results: Out of 83 patients, 23 died (27.71\%). AUROC curve for SOFA and MOD score were 0.514 and 0.510 respectively on admission, 0.587 and 0.512 on the second day of admission, 0.779 and 0.749 on the fourth day of admission and 0.978 and 0.824 after two weeks. Both systems were unreliable predictors of death for first 48 hours of admission. After 96 hours of admission, both systems represented an acceptable prediction ability, with no statistically significant difference between two tools $(P$ value $=0.850)$. In terms of outcome prediction, MOD scoring system performed good on fourteenth day with a significant difference when compared to excellent discriminant function of SOFA ( $P$ value $=0.027$ ).

Conclusions: During the 48 hours of admission, none of scoring tools showed a reliable function of predicting the ICU mortality. They represented an acceptable discriminative ability after the fourth day of admission and better predictive ability after the fourteenth day of admission. After two weeks of admission, SOFA is superior to MODS in outcome prediction.

Keywords: Multi-organ dysfunction syndrome; Sequential organ failure assessment score; Traumatic brain injury; Outcome assessment

\section{Introduction}

Traumatic Brain Injury (TBI) is an international socioeconomic problem. As estimated by World Health Organization it will be the third cause of burden of disease by 2020 [1]. TBI remains among major causes of mortality and morbidity in children over 1 year of age and young adults worldwide [2,3]. High rates of mortality and unfavourable outcome caused by TBI, necessitates the clinical use of scoring systems for determining the severity of insult and early prediction of survival. Such measurements improve the clinical management and allocation of resources to prevent the progression of damage in high-risk cases. They also facilitate the qualification and comparison of patient care in different critical care settings and clinical trials [4-6].

Consequences of severe traumatic brain injury; death and disability, are not always related to neurological complications. Non-neurological organ damage independently affects the outcome. Multi Organ Dysfunction Syndrome (MODS) is a common plot of the clinical course of any patient who requires intensive care, including those with severe traumatic brain injury [7,8]. Sequential Organ Failure Assessment (SOFA) and Multiple Organ Dysfunction (MODS) score are non-neurological scoring systems applied for predicting the severity of organ failure and mortality in ICU settings. $[9,10]$. Many research works have been published citing the validation of a single organ failure scoring system, or comparing the performance of two scoring systems $[11,12]$. Few studies compared two scoring systems similar or identical to our study but in general ICU patients and not in neurosurgical ICU setting [13-15]. Zygun et al. compared two scoring systems MODS and SOFA in patients with severe type head trauma and introduced SOFA as a superior prognostic tool compared to MODS [16]. In our previous works we compared two scoring systems compartment by compartment and assessed the correlation of each compartment to the outcome of patients admitted to NICU $[17,18]$. The aim of this study was to compare the ability of these two scoring systems in predicting the hospital mortality of severe traumatic brain injury.

\section{Materials and Methods}

Setting: This descriptive-analytic study was performed at neurosurgical ICU of Poursina Hospital, a level I trauma center specialized in the treatment of multiple trauma patients. Eighty 
Citation: Ramtinfar S, Chabok Sh Y, Chari AJ, Leili EK (2016) Predicting the Destiny after Severe Traumatic Brain Injury; Multi Organ Dysfunction Syndrome (MODS) or Sequential Organ Failure Assessment (SOFA)? J Neurol Neurophysiol 7: 408. doi: $10.4172 / 2155-9562.1000408$

Page 2 of 5

three patients with severe traumatic brain injury admitted to ICU between November 2012 and December 2013 were enrolled.

\section{Study design}

Patients were selected when they first admitted to the emergency department of the Poursina hospital. Severe TBI was defined as a TBI resulting in at least one of the following: an initial resuscitated (systolic blood pressure $>90 \mathrm{mmHg}$ and arterial oxygen saturation $>90 \%$ ) Glasgow coma score (GCS) of 8 or less on first evaluation by medical services; a post-resuscitation GCS of 8 or less on admission, without any sedation; need for intracranial pressure monitoring; or the presence of a clinical herniation syndrome as verified by trauma center physicians [16]. Patients with renal, liver, cardiac, and lung trauma and a positive history of past medical problems in these vital organs and those with unreliable past medical history, were omitted from the study. SOFA and MOD scores were collected daily. Organ dysfunction was identified by calculating both scoring systems at a single point in the morning during all days of ICU stay.

Descriptive statistical analysis was performed using SPSS version 21. In order to compare the mean values Mann-Whitney test, Student $\mathrm{t}$ test, chi-square and Pearson tests were used. In order to assess the discrimination ability of scoring systems, area under the receiver operating characteristic (AUROC) curve were used. $\mathrm{P}$ values $<0.05$ considered to be statistically significant.

\section{Results}

A total of 83 patients with severe head injury were included in this study. All of them admitted to ICU and had indications for ICU stay for a period of at least 14 days. Overall 23 patients $(27.71 \%)$ died during ICU stay. Mean age of all participants was $33 \pm 18$ years and the majority of cases were male (93.97\%). Demographic data are shown in Table 1.

\begin{tabular}{|l|c|}
\hline Study population $(\mathbf{n}=\mathbf{8 3})$ & Mean \pm SD \\
\hline Age (years) & $33 \pm 18$ \\
\hline Gender (F/M) & $5 / 78(93.97)$ \\
\hline Length of stay (days) & 12 \\
\hline APACHE II & $14 \pm 3$ \\
\hline Mortality & $23(27.71)$ \\
\hline
\end{tabular}

Table 1: Basic demographic features of study population.

\begin{tabular}{|l|c|c|}
\hline Time & SOFA (Mean \pm SD) & MODS (Mean \pm SD) \\
\hline Initial & $5.5 \pm 1.6$ & $5.4 \pm 1.6$ \\
\hline 48 hour & $6.3 \pm 1.8$ & $5.8 \pm 1.9$ \\
\hline 96 hour & $6 \pm 2.36$ & $5.8 \pm 2$ \\
\hline Final & $5 \pm 4$ & $5.6 \pm 4.1$ \\
\hline Maximum & $8.4 \pm 2.4$ & $8 \pm 2.19$ \\
\hline
\end{tabular}

Table 2: Mean values of SOFA and MOD score for different days.
The mean value of MODS and SOFA scores, calculated on first, second, fourth and fourteenth day of admission are summarized in Tables 2 and 3. As noted, both predicting systems showed higher scores in non-survivors than survivors.

\begin{tabular}{|l|c|c|c|c|}
\hline Time & $\begin{array}{c}\text { SOFA } \\
\text { Survivors }\end{array}$ & $\begin{array}{c}\text { SOFA Non- } \\
\text { Survivors }\end{array}$ & $\begin{array}{c}\text { MODS } \\
\text { Survivors }\end{array}$ & $\begin{array}{c}\text { MODS Non- } \\
\text { Survivors }\end{array}$ \\
\hline Initial & $5.5 \pm 1.6$ & $5.7 \pm 1.7$ & $5.5 \pm 1.6$ & $5.5 \pm 1.8$ \\
\hline 48 hour & $6.1 \pm 1.8$ & $6.7 \pm 1.9$ & $5.8 \pm 1.8$ & $5.9 \pm 2.1$ \\
\hline 96 hour & $5.2 \pm 1.6$ & $7.8 \pm 2.8$ & $5.2 \pm 1.6$ & $7.1 \pm 2.3$ \\
\hline Final & $3 \pm 2$ & $9 \pm 2$ & $4 \pm 3.11$ & $8.7 \pm 3.6$ \\
\hline Maximum & $7.3 \pm 1.3$ & $10.6 \pm 2.3$ & $7.2 \pm 1.6$ & $9.8 \pm 2.3$ \\
\hline
\end{tabular}

Table 3: Comparison of SOFA and MOD score between survivors and non-survivors.

The AUROC curve of MODS and SOFA scores during ICU admission are shown in Table 4. On the day of admission the AUROC for the MOD score was 0.510 and for SOFA score was 0.514 . After 48 hours of admission it was 0.512 for MODS and 0.587 for SOFA. Both systems failed to predict mortality on first and second day of admission. After 96 hours AUROC curve was 0.749 for MODS and 0.779 for SOFA. They both showed an acceptable ability to predict outcome, with no difference between $(P$ value $=0.850)$. Area under ROC curve calculated after two weeks of admission was 0.978 for SOFA and 0.824 for MODS. SOFA represented an excellent ability and MOD scoring system performed good. After two weeks of admission SOFA was significantly superior to MODS in predicting mortality $(P$ value $=0.027$ ). AUROC curve calculated for maximum values of SOFA and MODS were 0.876 and 0.812 , showing an equally good discriminative ability for both systems (Table 4).

Area under ROC curve, when calculated for scores on fourteenth day, showed a good discriminative function for both tools and considering maximum scores during the ICU stay period, AUROC curve for SOFA showed an excellent discriminative function. Cut off points and sensitivity and specificity of both systems are shown in Table 5.

\begin{tabular}{|l|c|c|c|c|c|c|c|}
\hline Time & $\begin{array}{c}\text { (SOFA) } \\
\text { AUROC }\end{array}$ & SE & $\mathbf{9 5 \%} \mathbf{C l}$ & $\begin{array}{c}\text { (MODS) } \\
\text { AUROC }\end{array}$ & SE & $\mathbf{9 5 \%} \mathrm{Cl}$ & $P$-value \\
\hline Initial & 0.514 & 0.077 & $\begin{array}{l}0.363- \\
0.665\end{array}$ & 0.51 & 0.074 & $\begin{array}{l}0.365- \\
0.656\end{array}$ & - \\
\hline 48 hour & 0.587 & 0.072 & $\begin{array}{l}0.445- \\
0.728\end{array}$ & 0.512 & 0.072 & $\begin{array}{l}0.350- \\
0.631\end{array}$ & - \\
\hline 96 hour & 0.779 & 0.06 & $\begin{array}{l}0.662- \\
0.896\end{array}$ & 0.742 & 0.062 & $\begin{array}{l}0.621- \\
0.863\end{array}$ & 0.85 \\
\hline $\begin{array}{l}\text { After 2 } \\
\text { weeks }\end{array}$ & 0.978 & 0.013 & $0.952-1$ & 0.824 & 0.061 & $\begin{array}{l}0.705- \\
0.944\end{array}$ & 0.027 \\
\hline Maximum & 0.876 & 0.052 & $\begin{array}{l}0.773- \\
0.979\end{array}$ & 0.812 & 0.061 & $\begin{array}{l}0.692- \\
0.931\end{array}$ & 0.207 \\
\hline
\end{tabular}

Table 4: Area under ROC curves, standard errors and 95\% of confidence interval of SOFA and MOD scores for different days. 
Citation: Ramtinfar S, Chabok Sh Y, Chari AJ, Leili EK (2016) Predicting the Destiny after Severe Traumatic Brain Injury; Multi Organ Dysfunction Syndrome (MODS) or Sequential Organ Failure Assessment (SOFA)?. J Neurol Neurophysiol 7: 408. doi: $10.4172 / 2155-9562.1000408$

Page 3 of 5

\begin{tabular}{|l|c|c|c|c|c|c|}
\hline $\begin{array}{l}\text { Cut off } \\
\text { points }\end{array}$ & $\begin{array}{c}\text { After 2 } \\
\text { weeks }\end{array}$ & Sensitivity & Specificity & $\begin{array}{c}\text { Maximum } \\
\text { score }\end{array}$ & Sensitivity & Specificity \\
\hline $\begin{array}{l}\text { SOFA } \\
\text { score }\end{array}$ & 4.5 & $100 \%$ & 0.771 & 5.5 & $100 \%$ & 0.104 \\
\hline $\begin{array}{l}\text { MOD } \\
\text { score }\end{array}$ & 5 & $100 \%$ & 0.062 & 5.5 & $100 \%$ & 0.104 \\
\hline
\end{tabular}

Table 5: Optimal cut-off points, sensitivity and specificity of maximum SOFA and MOD scores and of scores on day fourteenth.

Figures 1 and 2 represent the AUROC curve of SOFA and MOD scoring system respectively, drawn for different days of admission.

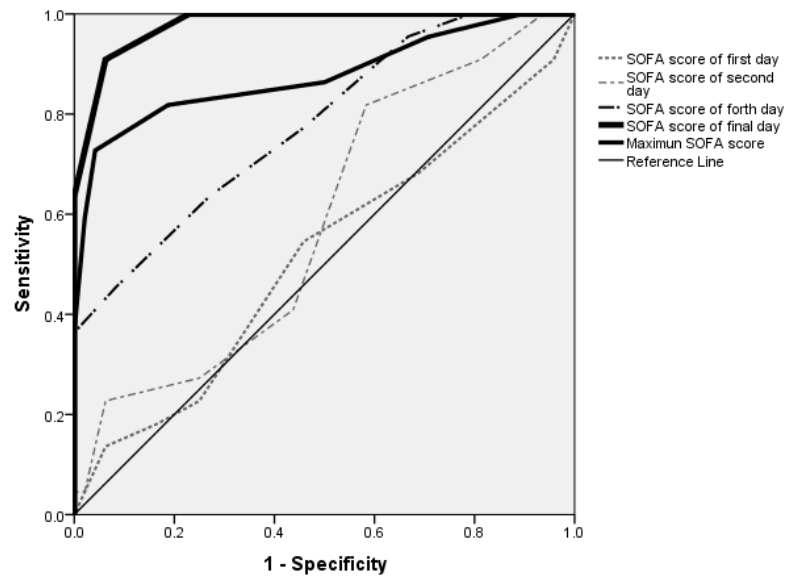

Figure 1: Area under receiver operating curve for maximum SOFA score and SOFA score on day $1,2,4$, and 14 after admission.

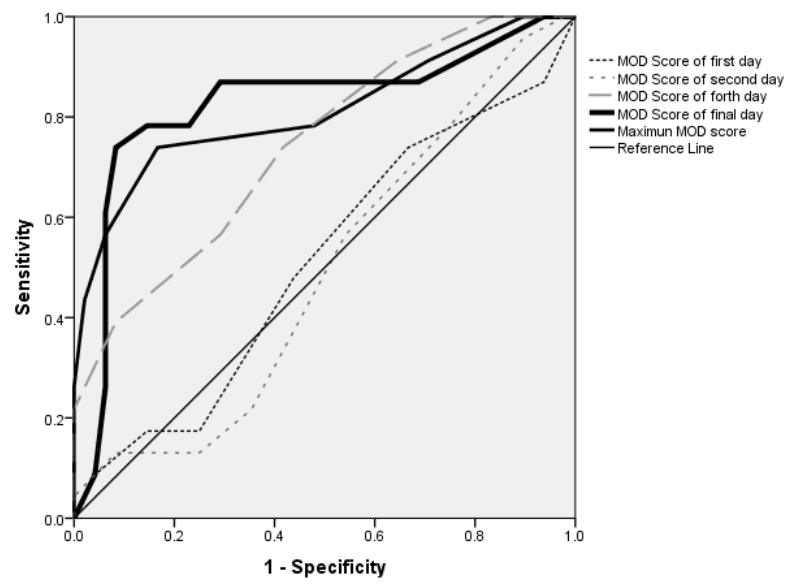

Figure 2: Area under receiver operating curve for maximum MOD score and MOD score on day 1,2,4 and 14 after admission.

\section{Discussion}

Our results show that none of these scoring systems has an acceptable discriminative ability on admission and until 48 hours after. From the day four and after, they both show an acceptable ability for outcome prediction. Our trial show that discriminative ability of both systems increase with elongation of ICU stay and SOFA represents an excellent discriminant function after two weeks, which is superior to MODS.

Defining the prognosis and research purposes is not the only goal of using predicting scoring systems in different subset of patients admitted to ICU setting $[17,18]$.

Scoring tools facilitate the evaluation of different types of ICU care and therapy models [19-21]. Predicting scoring systems serve as applicable tools for qualifying the medical care given to patients in different ICU settings and different hospitals. Managing hospital resources is another important utilization of these systems [22,23]. Many scoring systems including APACHEII, and III, Simplified Acute Physiology Score and Mortality Probability Models (MPM) have been used for outcome prediction [24-26]. The SOFA score was developed from a cohort of 1449 patients admitted to 40 ICUs in 16 different countries. It derived from a consensus conference held by European Society of Intensive Care and Emergency Medicine. SOFA score is calculated 24 hours after admission to ICU and every 48 hours thereafter with regard to function of respiratory, cardiovascular, hepatic, coagulation, neurologic and renal systems $[8,27]$. SOFA has shown as a reliable tool for outcome prediction [27,28]. MODS were presented as a quantifying tool of organ dysfunction, based on literature review from 1969 to 1993 and demonstrated a reliable ability for outcome prediction. Like SOFA, it evaluates the failure of six systems but not with the same parameters [29]. SOFA and MOD score have been used in many clinical trials to determine the outcome prediction ability in mixed ICU patients [5,7,28,29]. Few trials evaluated and compared the discriminative ability of these tools in patients with severe traumatic brain injury [16].

Zygun et al. calculated the scores of both systems in 209 patients with severe head injury. Few percentage of their patients had coagulation, hepatic or renal failure, so, in fact it was a comparison between cardiovascular and respiratory components of two systems. They demonstrated superior discriminative ability for cardiovascular component of SOFA in comparison with MODS. Interestingly, respiratory component had no relation to hospital mortality [16].

Severe traumatic brain injury is a category of heterogeneity. Most patients simultaneously suffer from damage to other internal organs. In addition to primary brain injury, secondary insults like hypoxia and hypotension after TBI are common [13,30-33]. Although nonneurologic organ failure poses a threat on survival, the effect of acute types of brain injury itself, like epidural and subdural hematoma and intracerebral hemorrhage must be taken into account. Severe traumatic brain injury has a mortality rate of $30 \%$. Both scoring tools evaluate the neurologic system only by calculating the GCS, with no consideration to CT findings, ICP monitoring or papillary function. This might be a reason for failure of SOFA and MODS in outcome prediction on admission and on first two days [32,33].

Both scoring tools evaluate the respiratory and cardiovascular and renal systems, but not in the same way. These variations may justify the superiority of SOFA over MODS. 
Citation: Ramtinfar S, Chabok Sh Y, Chari AJ, Leili EK (2016) Predicting the Destiny after Severe Traumatic Brain Injury; Multi Organ Dysfunction Syndrome (MODS) or Sequential Organ Failure Assessment (SOFA)? J Neurol Neurophysiol 7: 408. doi: $10.4172 / 2155-9562.1000408$

Page 4 of 5

Cardiovascular component of SOFA includes the mean arterial pressure and dosage of vasopressors, if used, but in MODS defined cardiovascular component, only pressure adjusted heart rate is calculated [15,16]. Mechanical ventilation, if indicated, must be considered in SOFA but not MOD-defined respiratory score, and in renal component, adding daily duresis is done only for calculation of SOFA score.

More studies need to be performed in order to compare available scoring systems for this specific subset of patients and to introduce strongly correlated prognostic factors for patients with severe type of head trauma. This study has been performed in a single trauma center and on a limited sample size of patients which both are considered as limitations to the study.

New simplified scoring systems for multiple trauma patients and for patients with traumatic brain injury have been developed and externally validated [4]. An ideal tool for subgroup of ICU patients with severe traumatic brain injury should include all other neurologic indicators in addition to GCS. Cost-effectiveness, external validation and a good discrimination and calibration will organize an excellent plot of a predictive scoring system [34].

\section{Compliance with Ethical Requirements}

The present study performed as a descriptive analytic trial, after the approval of Poursina hospital ethics committees and gathering informed consents.

\section{Conflict of Interest}

Shahrokh Yousefzadeh, Sara Ramtinfar, Jafari Chari A, Ehsan Kazemnezhad leili and Arsalan Alizadeh declare that they have no conflict of interest.

\section{References}

1. Yemon P, Pattani H, Silcocks P, Owen V, Fuller G (2011) Validation of the IMPACT outcome prediction score using the Nottingham Head Injury Register dataset. J trauma 71: 387-392.

2. Menon DK, Zahed C (2009) Prediction of outcome in severe traumatic brain injury. Curr Opin Crit Care 15: 437-441.

3. Maas AI, Stocchetti N, Bullock R (2008) Moderate and severe traumatic brain injury in adults. Lancet Neurol 7: 728-741.

4. Roozenbeek B, Lingsma HF, Lecky FE, Lu J, Weir J, et al. (2012) Prediction of outcome after moderate and severe traumatic brain injury: External validation of the IMPACT and CRASH models. Crit Care Med 40: 1609-1617.

5. Vincent JL, Moreno R (2010) Clinical review: scoring systems in the critically ill. Crit Care 14: 207.

6. Zygun DA, Kortbeek JB, Fick GH, Laupland KB, Doig CJ (2005) Nonneurologic organ dysfunction in severe traumatic brain injury. Crit Care Med 33: 654-660.

7. Corral L, Javierre CF, Ventura JL, Marcos P, Herrero JI, et al. (2012) Impact of non-neurological complications in severe traumatic brain injury outcome. J Crit Care 16: R44.

8. Vincent JL, De Mendonça A, Cantraine F, Moreno R, Takala J, et al. (1998) Use of the SOFA score to assess the incidence of organ dysfunction/failure in intensive care units: results of a multicentric, prospective study. Crit Care Med 26: 1793-1800.

9. Peres Bota D, Melot CH, Ferreira, Nguyen BAV, Vincent JL (2002) The multiple organ dysfunction score versus the sequential organ failure assessment score in outcome prediction. Intensive Care Med 28: 1619-1624.
10. Chawda MN, Hildebrand F, Pape HC, Giannoudis PV (2004) Predicting outcome after multiple trauma: which scoring system? Injury 35: 347-358.

11. Cabre L, Mancebo J, Solsona JF, Saura P, Gich I, et al. (2005) Bioethics Working Group of the SEMICYUC. Multicenter study of the multiple organ dysfunction syndrome in intensive care units, the usefulness of sequential organ failure assessment scores in decision making. Intensive Care Med 31: 927-933.

12. Fueglistaler PH, Amsler F, Schuepp M, Fueglistaler-Montali I, Attenberger C, et al. (2010) Prognostic value of sequential organ failure assessment and simplified acute physiology II score compared with trauma scores in the outcome of multiple-trauma patients. Am J Surg 200: 204-214.

13. Khwannimit B (2007) A comparison of three organ dysfunction scores: MODS, SOFA and LOD for predicting ICU mortality in critically ill patients. J Med Assoc Thai 90: 1074-1081.

14. Ho KM, Lee KY, Williams T, Finn J, Knuiman M, et al. (2007) Comparison of APACHE 11 score with organ failure scores to predict hospital mortality. Anaesthesia 62: 466-473.

15. Pettilä V, Pettilä M, Sarna S, Voutilainen P, Takkunen O (2002) Comparison of multiple organ dysfunction scores in the prediction of hospital mortality in the critically ill. Crit Care Med 30: 1705-1711.

16. Zygun D, Berthiaume L, Laupland K, Kortbeek J, Doig C (2006) SOFA is superior to MOD score for the determination of non-neurologic organ dysfunction in patients with severe traumatic brain injury: a cohort study. Crit Care 10: R115.

17. Ramtinfar S, Chabok SY, Chari AJ, Reihanian Z, Leili EK, et al. (2016) Early detection of nonneurologic organ failure in patients with severe traumatic brain injury: Multiple organ dysfunction score or sequential organ failure assessment?. Indian J Crit Care Med 20: 575-580.

18. Ramtinfar S, Chabok SY, Chari AJ, Reihanian Z, Leili EK, et al. (2016) Kidney disease improving global outcome for predicting acute kidney injury in traumatic brain injury patients. Acute Med 6: 90-94.

19. Knaus WA, Wagner DP, Zimmerman JE, Draper EA (1993) Variations in mortality and length of stay in intensive care units. Ann Intern Med 118: 753-761.

20. Bernard GR, Vincent JL, Laterre PF, LaRosa SP, Dhainaut JF, et al. (2001) Efficacy and safety of recombinant human activated protein $\mathrm{C}$ for severe sepsis. N Engl J Med 344: 699-709.

21. Anzueto A, Baughman RP, Guntupalli KK, Weg JG, Wiedemann HP, et al. (1996) Aerosolized surfactant in adults with sepsis-induced acute respiratory distress syndrome. Exosurf Acute Respiratory Distress Syndrome Sepsis Study Group. N Engl J Med 334: 1417-1421.

22. Zimmerman JE, Alzola C, Von Rueden KT (2003) The use of benchmarking to identify top performing critical care units: a preliminary assessment of their policies and practices. J Crit Care 18: 76-86.

23. Pronovost PJ, Angus DC, Dorman T, Robinson KA, Dremsizov TT, et al. (2002) Physician staffing patterns and clinical outcomes in critically ill patients: a systematic review. JAMA 288: 2151-2162.

24. Knaus WA, Draper EA, Wagner DP, Zimmerman JE (1985) APACHE II: a severity of disease classification system. Crit Care Med 13: 818-829.

25. Knaus WA, Wagner DP, Draper EA, Zimmerman JE, Bergner M, et al. (1991) The APACHE III prognostic system. Risk prediction of hospital mortality for critically ill hospitalized adults. Chest 100: 1619-1636.

26. Le Gall JR, Lemeshow S, Saulnier F (1993) A new Simplified Acute Physiology Score (SAPS II) based on a European/North American multicenter study. JAMA 270: 2957-2963.

27. Ferreira FL, Bota DP, Bross A, Mélot C, Vincent JL (2001) Serial evaluation of the SOFA score to predict outcome in critically ill patients. JAMA 286: 1754-1758.

28. Oda S, Hirasawa H, Sugai T, Shiga H, Nakanishi K, et al. (2000) Comparison of Sepsis-related Organ Failure Assessment (SOFA) score and CIS (cellular injury score) for scoring of severity for patients with multiple organ dysfunction syndrome (MODS). Intensive Care Med 26: 1786-1793. 
Citation: Ramtinfar S, Chabok Sh Y, Chari AJ, Leili EK (2016) Predicting the Destiny after Severe Traumatic Brain Injury; Multi Organ Dysfunction Syndrome (MODS) or Sequential Organ Failure Assessment (SOFA)? J Neurol Neurophysiol 7: 408. doi: 10.4172/2155-9562.1000408

Page 5 of 5

29. Marshall JC, Cook DJ, Christou NV, Bernard GR, Sprung CL, et al. (1995) Multiple organ dysfunction score: a reliable descriptor of a complex clinical outcome. Crit Care Med 23: 1638-1652.

30. Lim HB, Smith M (2007) Systemic complications after head injury: a clinical review. Anaesthesia 62: 474-482.

31. Sakr Y, Lobo SM, Moreno RP, Gerlach H, Ranieri VM, et al. (2012) Patterns and early evolution of organ failure in the intensive care unit and their relation to outcome. Crit Care 16: R222.
32. McHugh GS, Engel DC, Butcher I, Steyerberg EW, Lu J, et al. (2007) Prognostic value of secondary insults in traumatic brain injury: results from the IMPACT study. J Neurotrauma 24: 287-293.

33. Manley G, Knudson MM, Morabito D, Damron S, Erickson V, et al. (2001) Hypotension, hypoxia, and head injury: frequency, duration, and consequences. Arch Surg 136: 1118-1123.

34. Berthiaume L, Zygun D (2006) Non-neurologic organ dysfunction in acute brain injury. Crit Care Clin 22: 753-766. 